\title{
Cardiac and Ocular Pathologies in a Mouse Model of Mucopolysaccharidosis Type VI
}

\author{
OLIVER F. STRAUCH, JÖRG STYPMANN, THOMAS REINHECKEL, ELKE MARTINEZ, \\ WILHELM HAVERKAMP, AND CHRISTOPH PETERS
}

Institut für Molekulare Medizin und Zellforschung, Albert-Ludwigs-Universität Freiburg, D-79106

Freiburg, Germany [O.F.S., T.R., E.M., C.P.]; and Medizinische Klinik und Poliklinik C (Kardiologie und

Angiologie), ZPG Kleintierdiagnostik des IZKF Münster, Universitätsklinikum Münster, Westfälische

Wilhelms-Universität Münster, D-48149 Münster, Germany [J.S., W.H.].

\begin{abstract}
Mucopolysaccharidosis type VI (MPS VI) is a lysosomal storage disease caused by a deficiency of arylsulfatase B (ASB) which has its function in the sequential degradation of glycosaminoglycans (GAG). Targeted disruption of the ASB gene resulted in a mouse model of MPS VI that has been closely investigated for skeletal and chondral dysplasia. As ocular and cardiac impairment are also clinically important manifestations of the MPS VI syndrome, the present study was initiated for detailed biochemical, histologic and functional analysis of cornea, optic nerve and heart in ASB-deficient mice. Biochemical evidence for GAG-storage could be obtained for liver, kidney, spleen and myocardium as well as for heart valves, cornea and optic nerve from ASB-deficient mice. In MPS VI mice, histology revealed structural impairment of corneal stroma and epithelium as well as a thickening of the heart valves. According to histologic investigations, the optic nerve appeared not to be altered. However, GAG-storage in the dura mater could be demonstrated in MPS VI mice. Heart function was assessed by echocardiography. While the dimensions of MPS VI hearts were not altered, these hearts clearly showed decreased myocardial contraction and a $50 \%$ reduction of cardiac output. In addition, insufficiencies in the mitral and aortic valves were detected. Thus, ASBdeficient mice resemble the phenotype of human MPS VI not only in the skeletal but also in the ocular and cardiac symptoms. To our knowledge, these in vivo evaluations of heart function represent the first respective investigation of a MPS VI animal
\end{abstract}

\section{ABSTRACT}

model and should provide a valuable measure for therapy studies in the MPS VI mouse. (Pediatr Res 54: 701-708, 2003)

$\quad$ Abbreviations
ACC/AHA, American Collage of Cardiology (ACC) and
American Heart Association (AHA)
AML, Anterior mitral leaflet
AoV, aortic valve
ASB, arylsulfatase B, $N$-acetylgalactosamine-4-sulfatase, EC
3.1.6.12
DLVOT, diameter of left ventricular outflow tract
FS, fractional shortening ((LVEDD - LVESD)/LVEDD × 100)
GAG, glycosaminoglycan
IVS, interventricular septum
IVSed, end-diastolic diameter of interventricular septum
LA, left atrium
Laed, end-diastolic diameter of left atrium
LV, left ventricle
Lved, end-diastolic diameter of left ventricle
LVEDD, left ventricular end-diastolic diameter
LVESD, left ventricular end-systolic diameter
LVOT, left ventricular outflow tract
MPS, VI Mucopolysaccharidosis type VI, Maroteaux-Lamy
syndrome
MV, mitral valve
Pwed, end-diastolic diameter of posterior wall

Mucopolysaccharidosis type VI (MPS VI) or MaroteauxLamy syndrome is a lysosomal storage disease with autosomal recessive inheritance. It is caused by deficiency of arylsulfatase B (ASB, N-acetylgalactosamine-4-sulfatase, EC 3.1.6.12).

Received September 2, 2002; accepted March 12, 2003.

Correspondence: Christoph Peters, M.D., Institut für Molekulare Medizin und Zellforschung, Hugstetter Str. 55, D-79106 Freiburg, Germany; e-mail:petersc@ mm11.ukl.uni-freiburg.de

This study was supported by DFG grants (Pe 310/11-1 and -2 and SFB 556) and the Fonds der Chemischen Industrie (C.P. and T.R.).

O.F.S. and J.S. contributed equally to this paper.

DOI: 10.1203/01.PDR.0000084085.65972.3F
ASB is essential for desulfation of C4-linked sulfate esters from the non-reducing end of $\mathrm{N}$-acetylgalactosamine residues in the glycosaminoglycans dermatan sulfate and chondroitin4-sulfate (1). Consequently, mutation of the two ASB gene alleles results in impairment of glycosaminoglycan (GAG) degradation, subsequent lysosomal storage and urinary excretion of dermatan sulfate and other GAG species (2).

The clinical course of MPS VI patients shows great variability in terms of the severity of symptoms and the age of onset of the disease (1). Dysostosis multiplex is the leading symptom of mucopolysaccharidoses. Patients with severe MPS 
VI show an enlarged head and a deformed chest already at birth. Pelvic malformation and dysplasia of long bones cause growth retardation resulting in an ultimate height of 110-140 $\mathrm{cm}$ for severely affected patients. Restrictions in joint movement and claw-hand deformities can be observed. Besides malformation of the skeletal system, hepatosplenomegaly is a common symptom of MPS VI. MPS VI patients develop visual impairment caused by corneal clouding or involvement of the optic nerve $(3,4)$. Cardiac impairment is a frequent problem in the clinical management of MPS VI patients who show milder progression of the disease (5). Heart-valve insufficiencies as well as stenosis are frequently observed in MPS VI (6). Cardiomyopathy occurs in $20 \%$ to $30 \%$ of MPS VI patients (5), and most patients with severe MPS VI die of heart failure in their second or third decade (1). It should be noted that in contrast to the clinically similar mucopolysaccharidosis type 1H (MPS IH, Hurler syndrome) a primary involvement of the nervous system and mental retardation is not observed in MPS VI.

Only symptomatic therapy and allogenic bone marrow transplantation (7) is available at present for treatment of MPS VI. Currently an enzyme replacement therapy with ASB is in a clinical trial (http://www.biomarinpharm.com/BM_Clinica1AndDevelopmentPrograms_Aryplase.html). Because of the severity of symptoms and the reduction in life expectancy the development of curative therapy options, like enzyme replacement or gene therapy, is a top priority. The development of therapies largely relies on the availability of suitable animal models that resemble the disease in question. Feline $(8,9)$ and rat $(10,11)$ strains as well as a dog $(12)$ with ASB deficiency have been discovered with subsequent use of these MPS VI models for therapy studies (13-16). However, these MPS VI animal models do not allow the analysis of larger cohorts. This is a major drawback in attempts to develop gene therapy strategies for which many parameters need to be optimized (17). Thus, in previous work the mouse ASB gene has been disrupted by homologous recombination to obtain an MPS VI mouse model (18).

The phenotype of ASB-deficient mice is highly reminiscent of the pathologic characteristics of MPS VI (18). The functional inactivation of the ASB gene results in facial dysmorphy, pelvic and costal abnormalities and shortening of long bones. In addition, perturbed and persistent growth plates as well as storage of glycosaminoglycans (GAG) in liver and heart has been demonstrated (18). The present investigations were performed to provide a more detailed analysis of cornea, optic nerve and heart in the MPS VI mouse model for comparison with the clinical manifestation of MPS VI in patients.

\section{METHODS}

Experimental animals. ASB-deficient mice have been generated by gene targeting in mouse embryonic stem cells as described (18). For the present study, chimeric male mice were bred with 129S2 (former 129/SvPas) females to establish an inbred strain. The mice were conventionally housed in a controlled environment with a temperature of $21^{\circ} \mathrm{C} \pm 1$ and a $12 \mathrm{~h}$ day/night cycle. Mice were kept in macrolon cages and had access to standard food pellets and tap water ad libitum. All subsequent experiments including echocardiographic recordings were performed in accordance with institutional regulations.

Histologic analyses. For light microscopy, 6-mo-old mice were examined. Six ASB-deficient mice and six wild-type controls ( 3 males and 3 females each) were anesthetized by intraperitoneal injection of $100 \mathrm{mg} / \mathrm{kg}$ ketamine (Ketavet $\AA$, Pharmacia \& Upjohn, FRG) and $5 \mathrm{mg} / \mathrm{kg}$ xylazine (Rompun ${ }^{\circledR}$, BayerVital, FRG) followed by perfusion through the left ventricle with $4 \%$ fresh paraformaldehyde in calcium- and magnesium-free PBS (pH 7.4). Total heart, liver, kidney, and skull were sampled, postfixed for $4 \mathrm{~h}$ in $4 \%$ paraformaldehyde/PBS solution and embedded in paraffin. The skull was subjected to EDTA solution for decalcification for 2 weeks. Subsequently the cornea and optic nerve were represented in situ. Sections of 5-6 $\mu \mathrm{m}$ were stained with Mowry's colloidal iron solution (19) and analyzed by light microscopy (Axioplan, Zeiss, FRG).

Biochemical analyses. Glycosaminoglycan (GAG) content was determined by an adapted dimethylmethylene blue colorimetric assay in tissues of up to thirteen 4- to 6-mo-old male and female mice per ASB-genotype (exact numbers indicated in the figures) (20). Briefly, $50 \mathrm{mg}$ samples of liver, kidney, spleen and from the tip of the heart (including myocardium of the left and right ventricle) as well as $3-5 \mathrm{mg}$ of leaflets (including chordae tendinea) from the mitral and aortic valve, total optic nerve and total cornea were obtained with the help of a stereomicroscope. Tissues were homogenized by ultrathurax in $0.5 \mathrm{~mL}$ or $0.3 \mathrm{~mL}$ (small samples) of $50 \mathrm{mM}$ Tris/ $\mathrm{HCl}$ $(\mathrm{pH}$ 7.5). The homogenates were incubated with $0.8 \mu \mathrm{g} / \mathrm{mL}$ proteinase $\mathrm{K}$ at $55^{\circ} \mathrm{C}$ for $4 \mathrm{~h}$. Subsequently, proteinase $\mathrm{K}$ was inactivated for $15 \mathrm{~min}$ at $100^{\circ} \mathrm{C}$, and samples were subsequently treated with DNAseI at $37^{\circ} \mathrm{C}$ for $1 \mathrm{~h}$. Suspensions were chloroform-extracted and gel-filtrated through Sephadex G25. After addition of $0.5 \mathrm{~mL}$ trimethylethylene blue solution (20) to $0.5 \mathrm{~mL}$ of this extract, absorption at $535 \mathrm{~nm}$ was compared with a standard curve of chondroitin sulfate B (Sigma Chemical Co., Germany). Protein determinations were performed in $5 \mu \mathrm{L}$ homogenate taken before proteinase $\mathrm{K}$ digestion using a commercially available assay ( $D C$ Protein Assay, BioRad, Germany), with BSA as standard.

M-mode and Doppler-echocardiography. Echocardiographic examination of 19 one-year-old male mice (10 ASBdeficient and 9 wild-type controls) was double-blinded with regards to genotype of the mouse and calculation of results. After intraperitoneal sedation with a combination of $50 \mathrm{mg} / \mathrm{kg}$ ketamine (Ketavet ${ }^{\circledR}$, Pharmacia \& Upjohn, FRG) and $5 \mathrm{mg} / \mathrm{kg}$ xylazine (Rompun ${ }^{\circledR}$, BayerVital, FRG), the chests of the mice were precordially shaved using a commercially available electro-shaver. Subsequently, the mice were secured in a supine position to a warm waterbed heated to $40^{\circ} \mathrm{C}$ and angled $45^{\circ}$ to the left. Single channel ECG-electrodes fixed to the limbs were used to identify the temporal distance of clear signals of the QRS-complex and to obtain data on the heart rate. Transthoracic echocardiography was performed with a commercially available digital cardiac ultrasound machine equipped with either a $6-12-\mathrm{MHz}$ short focal length-phased array transducer or a $15-\mathrm{MHz}$ linear-array transducer (Phillips, HewlettPackard, Sonos 5500, B1-software package, Andover, U.S.A). 
During examination, images with the $6-12-\mathrm{MHz}$ short focal length-phased array transducer were obtained by use of an acoustic stand-off. This stand-off was secured to the tip of the transducer in the form of an index finger which was cut from a latex glove filled with $1.5 \mathrm{~cm}$ of ultrasound coupling gel centrifuged at $3000 \times g$ to remove air bubbles. Another layer of $2 \mathrm{~cm}$ centrifuged, warmed ultrasound coupling gel was put on the hairless chest of the mice. While obtaining the pictures of the heart, no excessive pressure was applied to the thorax of the mice so that deformation of the thorax was avoided. Parasternal long-axis and short-axis views were obtained at a frame rate of 300 per second and setting the variable depth of the zoom box at $2-4 \mathrm{~cm}$. All data were stored as digitally recorded loops and digitally recorded pictures on magnetooptical discs. M-mode and Doppler recordings were performed at a sweep speed of $150 \mathrm{~mm} / \mathrm{s}$. Echocardiographic measurements were performed according to the ACC/AHA Guidelines for the Clinical Application of Echocardiography. M-Mode data of left ventricular septal (IVSed) and posterior wall thickness (PWed) at end-diastole as well as end-diastolic and -systolic dimensions of the left ventricle (LVEDD, LVESD) were acquired in the parasternal long axis view following the leading edge to leading edge method of three consecutive cycles (21). Percentage of fractional shortening (FS) as an index of left ventricular contraction was calculated with the standard equation FS\% $=($ LVEDD - LVESD $) /$ LVEDD $\times 100(22,23)$. Pulsed wave Doppler signals were achieved by placing the sample volume parallel to flow during long-axis view into left ventricular outflow tract and ascending aorta for systolic outflow of the left ventricle as well as apical to the mitral valve within left ventricle for diastolic inflow. The left atrium was mapped for mitral regurgitation by pulsed wave Doppler. In addition, mitral and aortic valves were examined for regurgitation by color flow Doppler. Cardiac output was calculated using heart rate, velocity time integral of the Doppler-signals in the left ventricular outflow tract and the end-diastolic diameter of the left ventricular outflow tract.

Statistical analyses. Values were expressed by means and their respective standard errors or standard deviations. Using the two-tailed $t$ test and the Wilcoxon rank sum test, a $p<0.05$ was considered to indicate statistically significant differences between the groups investigated.

\section{RESULTS}

MPS VI mice revealed a 4- to 15-fold increase of glycosaminoglycan (GAG) content in tissues of 6-mo-old animals compared with wild-type controls (kidney: MPS VI, 7.35 $\mu \mathrm{g} / \mathrm{mg}$ protein \pm 1.57 ; controls, $1.56 \mu \mathrm{g} / \mathrm{mg} \pm 0.66$; spleen: MPS VI, $12.15 \mu \mathrm{g} / \mathrm{mg} \pm 1.8$; controls, $1.22 \mu \mathrm{g} / \mathrm{mg} \pm 0.7$; liver: MPS VI, $11.17 \mu \mathrm{g} / \mathrm{mg} \pm 1.53$; controls, $0.72 \mu \mathrm{g} / \mathrm{mg} \pm$ $0.72 ; p<0,01)$. Based on these findings, the GAG-assay was used to further investigate relevant MPS VI pathologies in the mouse. Corneal clouding is frequently observed in MPS VI patients. However, MPS VI mice do not develop the end stage of this condition but show a significantly increased amount of GAG in the cornea (Fig. 1A). Accordingly, GAG accumulation could be demonstrated by Mowry-staining of histologic sec- tions of MPS VI cornea (Fig. 1, C-E). In addition, the corneal sections of MPS VI mice showed marked histomorphological alterations. In comparison to wild-type mice, which are characterized by regular arrayed stroma and a 4- to 6-layered corneal epithelia (Fig. 1B), the corneal alterations were considerably heterogeneous between individual MPS VI mice (Fig. 1, C-E) and ranged from mild disarrangement of fibrils to severe stromal disarray with large fissures. Basal cells of the MPS VI corneal epithelium appeared to be flattened with a distortion of nuclei. In most cases, the corneal epithelium in MPS VI mice showed reduced thickness and a loss of the typical cell alignment (Fig. 1, $C$-E). Furthermore, optic nerves of MPS VI mice showed a small but statistically significant increase in GAG content compared with wild-type mice (Fig. $1 A$ ). The accumulation of storage material is most likely to occur in the collateral sheaths of the optic nerve. However, these pathologic alterations do not affect the dura mater homogenously because dura mater involvement was detectable only in one of six MPS VI mice investigated by histology (data not shown). No alterations could be observed in arachnoidea or pia mater, and there was no evidence of nerve atrophy in ASB mutant mice (data not shown).

Cardiomyopathy and alteration of heart valves constitute serious clinical complications of MPS VI that often determine the prognosis of the disease. The myocardium of MPS VI mice compared with wild-type mice contains a 5 -fold excess of GAG (Fig. 2A). By histology, wild-type mice show cardiomyocytes with fine cross striations and only a small amount of connective tissue (Fig. 2B). In the myocardium of MPS VI GAG storage occurred exclusively in interstitial cells, indicated by areas of blue color with ballooned and vacuolated cells (Fig. 2C). Compared with the myocardium, the heart valves of wild-type mice contained relatively high amounts of GAG (Fig. 2A). However, heart valves of MPS VI mice contained about twice as much GAG as valves of control hearts. Striking differences were found in the histomorphology of heart valves from MPS VI and control mice. Normal leaflets of wild-type mice are less than $25 \mu \mathrm{m}$ in diameter and exhibit only a thin band of GAG containing connective tissue (colored blue by Mowry staining; Fig. 2D). Heart valves of all investigated MPS VI mice showed a considerable thickening and GAGs were detectable throughout the entire valve (Fig. 2, $E-G$ ). In addition, an enlargement of cells that contain vacuoles and a higher cell number as observed in leaflets from wild-type hearts were detected in ASB-deficient mice (Fig. 2, E-D).

The functional relevance of these histopathological changes in myocardium and heart valves of MPS VI mice was assessed in vivo by Doppler-echocardiographic investigations of 10 one-year-old male MPS VI and 9 age- and sex-matched control mice. MPS VI mice did not reveal marked alterations in morphology or size of the heart. Of special interest, there was no significant size difference in the end-diastolic diameters of left atrium, left ventricle and the diameters of left ventricular outflow tract (LVOT) and aortic valve (Table 1). This corresponds to the gross morphology of the hearts evaluated by post mortem inspection (data not shown). M-Mode assessment of left ventricular posterior wall (PWed) and the interventricular septum (IVSed) did not reveal significant changes of myocar- 
A
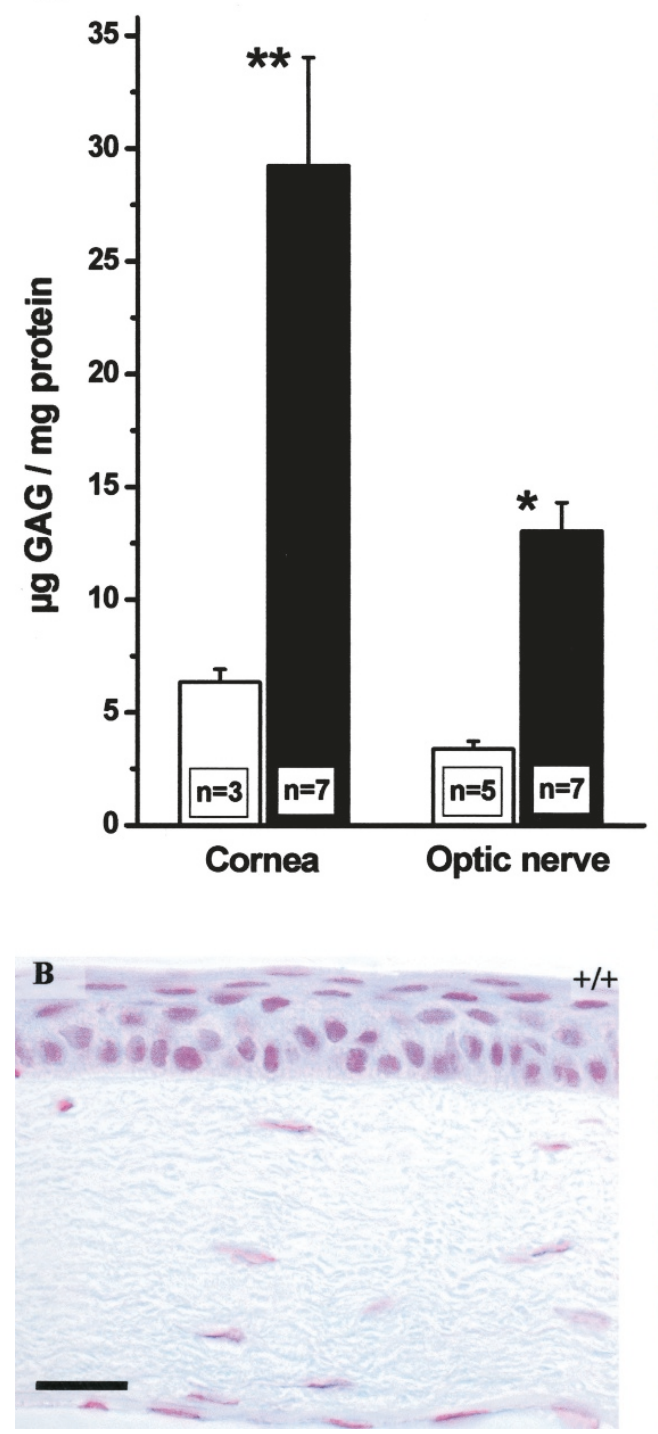

C

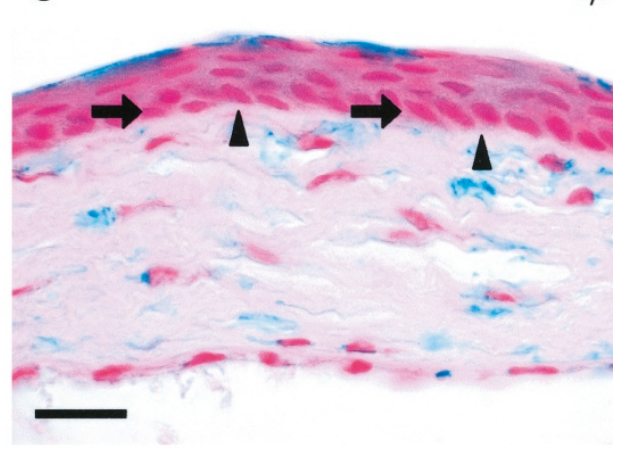

D

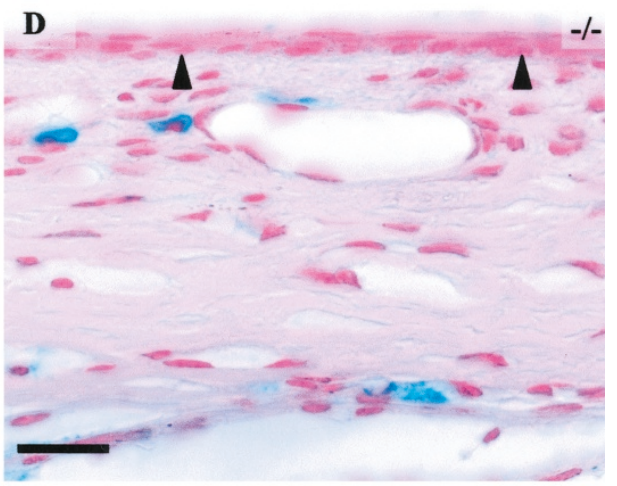

E

$-/-$

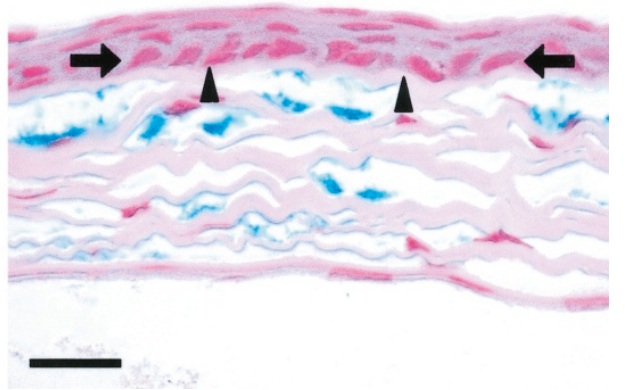

Figure 1. Examination of cornea and optic nerve of 6-mo-old wild-type (+/+) and MPS VI (-/-) mice. (A) GAG storage in wild-type (open bars) and MPS VI (black bars) mice in the cornea and optic nerve respectively. MPS VI mice show a significantly increased amount of GAG in the cornea and optic nerve compared with wild-type mice. Results are expressed as the mean \pm SE. Statistical significance of MPS VI $v s$ wild type: ${ }^{*} p<0.01$; $* * p<0.05$ (Wilcoxon rank sum test). (B-E) light microscopy of cornea, Mowry's colloidal staining (blue color) reveals glycosaminoglycans (GAG) in corneal layers. Bars indicate $20 \mu \mathrm{m}$. $(B)$ wild-type mice with a 4-6 layered cornea epithelium, a basic layer of cylindrical cells and regularly arrayed stroma. (C-E) The corneal stroma of MPS VI mice shows different forms of alterations ranging from mild disarrangement of fibrils to severe forms with large fissures. Occasionally the layer of the corneal epithelium (arrowheads) is condensed to $2-3$ layers $(C)$, and a loss of the typical cell alignment appears in all MPS VI corneas. Cells of the basal layer of the epithelium appear flattened with distorted nuclei (arrows).

dial wall thickness (Table 1). In contrast and most importantly, the systolic and diastolic functional properties of hearts of MPS VI mice were significantly and severely impaired. In MPS VI hearts the left ventricular diameter at the end of systole (LVESD) was significantly enlarged, while the left ventricular diameter at the end of diastole (LVEDD) was not changed significantly (Table 2). There was normal contraction movement of the interventricular septum during systole and paradox movement of the IVS was not noted during the complete course of heart action. Thus, fractional shortening of the myocardium from MPS VI mice was reduced to about two thirds of the wild-type value (Table 2). A significantly lowered velocity of blood flow and reduced pressure gradients across the aortic and mitral valves have been detected in MPS VI mice
(Table 2). The impaired diastolic properties of the MPS VI mice compared with wild-type mice are demonstrated by a significant reduction of the $V_{\max }$ of the mitral E-Wave of $38 \%$ representing the impaired diastolic filling of the left ventricle. $V_{\max }$ of A-Wave, representing the atrial contraction, was not significantly reduced in MPS VI mice. The ratio of the velocities of E- and A-Wave were 2.0 in the MPS VI mice and 2.45 in the wild-type mice. The maximal velocity of blood flow in the aorta was maintained almost at normal level. However, the cardiac output in MPS VI mice was almost half of wild-type controls (Table 2). Mitral valve thickening was detected by echocardiography in four of the ten investigated MPS VI mice. Two of these four MPS VI mice showed mitral regurgitation (Fig. 3). In addition, one mouse with thickening of the right 

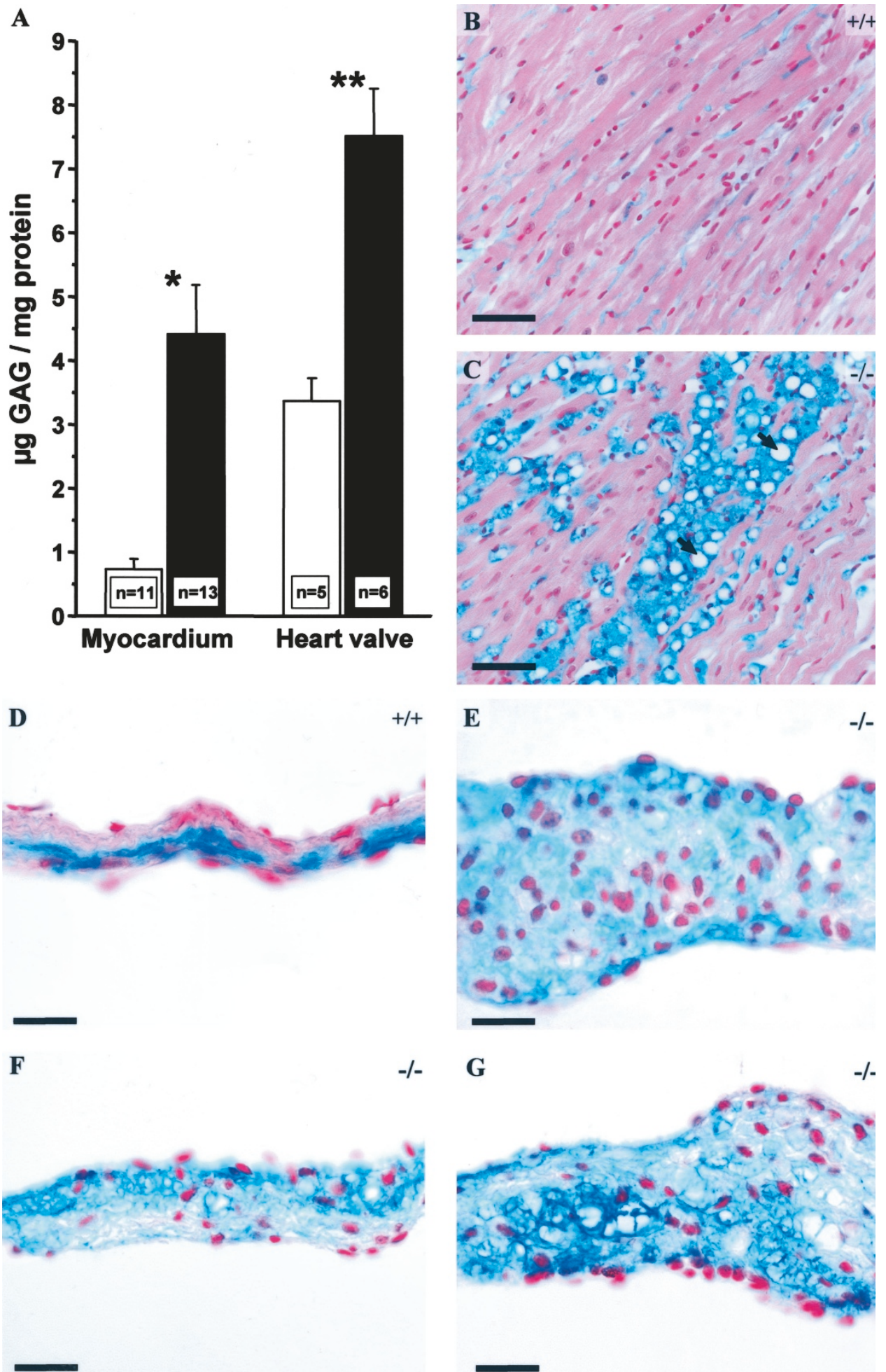

Figure 2. Examination of myocardium and heart valves of 6-mo-old wild-type and MPS VI mice. (A) GAG storage in wild-type (open bars) and MPS VI (black bars) mice in myocardium and heart valves respectively (mitral and aortic valves were combined for each animal). MPS VI mice show a significantly increased amount of GAG in myocardium and heart valves compare with the wild-type mice. Results are expressed as the mean \pm SE. Statistical significance of MPS VI $v s$ wild type: ${ }^{*} p<0.001 ;{ }^{* *} p<0.01$ (Wilcoxon rank sum test). $(B, C)$ Mowry staining for GAG detection (blue color) in myocardium from wild-type (+/+) and MPS VI $(-/-)$ mice. Bars indicate $50 \mu \mathrm{m}$. $(D)$ Mowry staining of a mitral valve from one wild-type mouse. The valve (approximately $20 \mu \mathrm{m}$ in diameter) exhibits a typical compact structure with a physiologic amount of GAG (blue color). (E-G) Mowry staining of mitral valves from three MPS VI mice ( $-/-$ ). Valves appear markedly thickened and show ballooned and vacuolated interstitial cells with high GAG load. Bars indicate $20 \mu \mathrm{m}(D-G)$. 
Table 1. Doppler-echocardiographic findings in MPS VI mice in comparison to wild-type mice: heart dimensions

\begin{tabular}{lccc}
\hline & $\begin{array}{c}\text { Wild-type mice } \\
(n=9)\end{array}$ & $\begin{array}{c}\text { MPS VI mice } \\
(n=10)\end{array}$ & $p$ \\
\hline LAed (mm) & $2.5 \pm 0.24$ & $2.3 \pm 0.24$ & 0.21 \\
LV-length (mm) & $6.2 \pm 0.47$ & $5.9 \pm 0.55$ & 0.29 \\
IVSed (mm) & $0.9 \pm 0.07$ & $0.9 \pm 0.17$ & 0.43 \\
PWed (mm) & $1.0 \pm 0.13$ & $1.0 \pm 0.09$ & 0.12 \\
AoV (mm) & $1.3 \pm 0.17$ & $1.4 \pm 0.20$ & 0.46 \\
LVOT (mm) & $1.1 \pm 0.11$ & $1.1 \pm 0.13$ & 0.87 \\
Ratio LA/AoV & $1.9 \pm 0.38$ & $1.7 \pm 0.29$ & 0.21 \\
\hline
\end{tabular}

LAed, diameter of left atrium; LV-length, length of left ventricle; IVSed, end-diastolic thickness of interventricular septum; PWed, end-diastolic posterior wall thickness; AoV, diameter of aortic valve; LVOT, diameter of left ventricular outflow tract. Results are expressed as the mean \pm SD. Statistical level $(p)$ of MPS VI versus wild-type mice by Student's $t$-test.

aortic cusp could be demonstrated to have aortic insufficiency (not shown).

\section{DISCUSSION}

Since dysostosis multiplex is the leading symptom of MPS VI, skeletal impairment has received most attention in the previously performed MPS VI animal studies. However, it is known that cardiac impairment represents a serious clinical problem in MPS VI and that many patients die from heart failure (5). Because the development of novel MPS VI therapy options with the help of animal models is an important goal, it is appropriate to establish not only biochemical and histologic parameters of heart involvement in MPS VI, but to also assess heart function in vivo. During the past few years, noninvasive
Table 2. Doppler-echocardiographic findings in MPS VI mice in comparison to wild-type mice: heart function

\begin{tabular}{lccc}
\hline & $\begin{array}{c}\text { Wild-type mice } \\
(n=9)\end{array}$ & $\begin{array}{c}\text { MPS VI mice } \\
(n=10)\end{array}$ & $p$ \\
\hline LVESD $(\mathrm{mm})$ & $2.5 \pm 0.32$ & $2.9 \pm 0.23$ & 0.005 \\
LVEDD $(\mathrm{mm})$ & $4.1 \pm 0.35$ & $3.9 \pm 0.34$ & 0.303 \\
FS $(\%)$ & $38.9 \pm 4.60$ & $25.6 \pm 4.72$ & $<0.001$ \\
Ao Vmax $(\mathrm{cm} / \mathrm{s})$ & $72.4 \pm 7.41$ & $51.7 \pm 9.70$ & $<0.001$ \\
Ao PGmax $(\mathrm{mmHg})$ & $2.1 \pm 0.41$ & $1.1 \pm 0.40$ & $<0.001$ \\
Ao PGmean $(\mathrm{mmHg})$ & $1.0 \pm 0.26$ & $0.6 \pm 0.18$ & $<0.001$ \\
MV PGmax $(\mathrm{mmHg})$ & $1.3 \pm 0.48$ & $0.5 \pm 0.21$ & $<0.001$ \\
MV PGmean $(\mathrm{mmHg})$ & $0.5 \pm 0.15$ & $0.1 \pm 0.06$ & $<0.001$ \\
MV E-Wave $(\mathrm{cm} / \mathrm{s})$ & $59.6 \pm 9.02$ & $37.3 \pm 8.70$ & $<0.001$ \\
MV A-Wave $(\mathrm{cm} / \mathrm{s})$ & $24.4 \pm 10.51$ & $18.0 \pm 5.88$ & 0.114 \\
Vmax Ao asc. $(\mathrm{cm} / \mathrm{s})$ & $77.4 \pm 8.9$ & $65.3 \pm 20.7$ & 0.124 \\
Vmax Ao desc. $(\mathrm{cm} / \mathrm{s})$ & $60.1 \pm 7.8$ & $53.6 \pm 13.8$ & 0.237 \\
Cardiac output $(\mathrm{ml} / \mathrm{min})$ & $12.2 \pm 2.44$ & $6.8 \pm 1.87$ & $<0.001$ \\
\hline
\end{tabular}

LVESD, left ventricular end-systolic diameter; LVEDD, left ventricular end-diastolic diameter; FS, fractional shortening; Ao Vmax, maximum velocity of flow in pw-doppler over aortic valve; Ao PGmax, maximum aortic pressure gradient; Ao PGmean, average aortic pressure gradient; MV PGmax, maximum mitral valve pressure gradient; MV PGmean, average mitral valve pressure gradient; MV E-Wave, maximum velocity E-wave flow, MV AWave, maximum velocity of A-wave flow; Vmax Ao des., maximum velocity of blood flow in aorta ascendens. Results are expressed as the mean \pm SD. Statistical level $(p)$ of MPS VI versus wild-type mice by Student's $t$-test.

Doppler-echocardiographic assessment of hemodynamics and cardiovascular function for the phenotyping of genetically modified mice has been developed in a reliable research tool. The use of inbred mouse strains that are kept under controlled housing conditions results in reduction of variation in physiologic parameters between individual mice. Echocardiographic
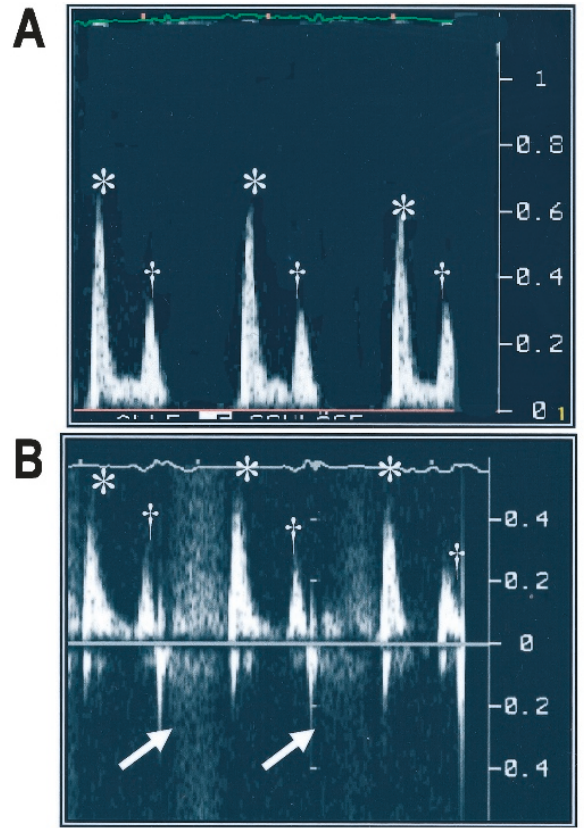

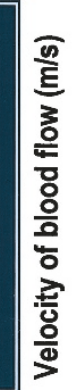

time

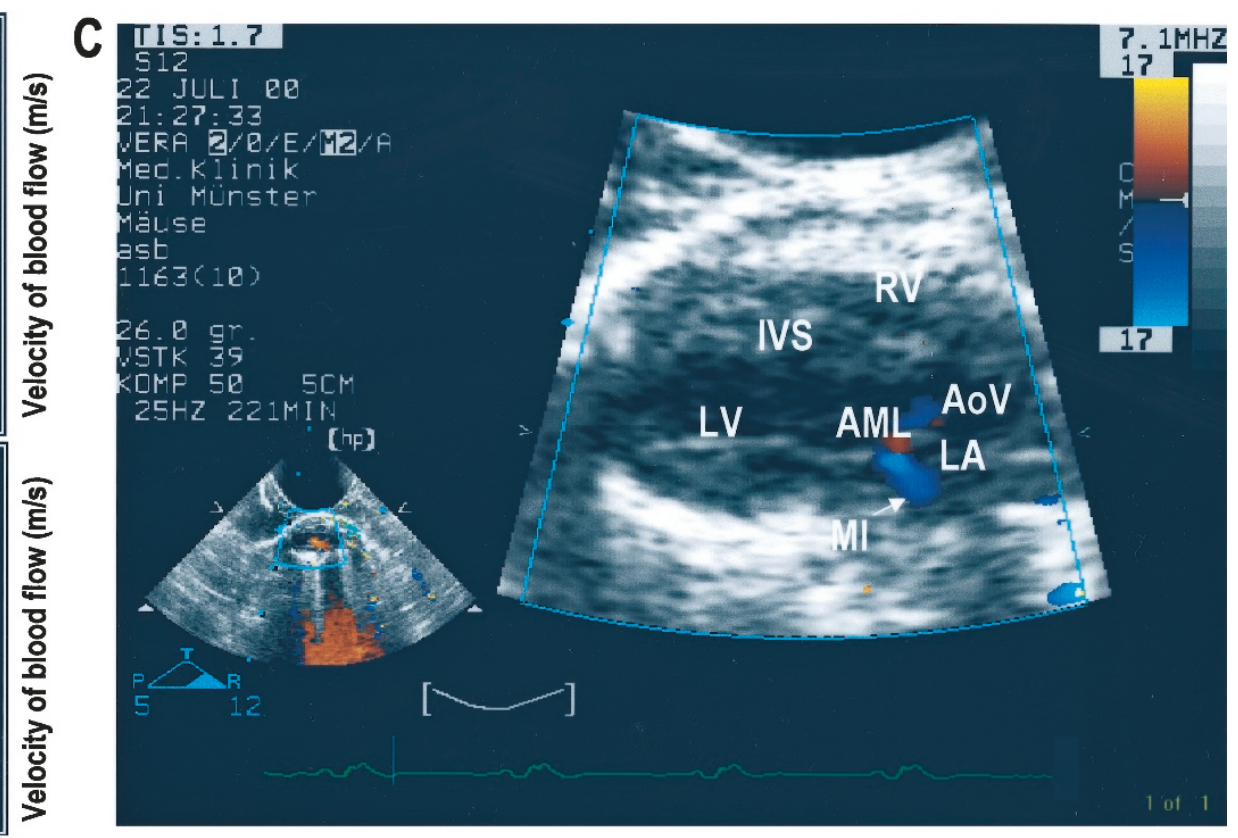

Figure 3. Functional assessment of mouse mitral valves by Doppler-echocardiography. $(A)$ Pulse wave Doppler-echocardiography in a wild-type mouse at 12 mo of age, $(B)$ Pulse wave Doppler-echocardiography in a MPS VI mouse at 12 mo of age. E-Wave $(*)$ in wild-type mice is twice as fast compared with MPS VI, while there is no difference in the A-waves $(\dagger) .(C)$ Color flow Doppler-echocardiography of the same mouse as in $(B)$. Insufficiency backflow $($ white arrows) was only detected in the heart of this MPS VI mouse. RV, right ventricle; IVS, interventricular septum; AML, anterior mitral leaflet; LA, left atrium; AoV, aortic valve. 
indices of left ventricular function can reliably describe heart performance in genetically targeted mice and color flow and pulsed wave Doppler are able to identify insufficiencies of the aortic and mitral valves in mice (24-27).

Since MPS VI is a rare disease with an incidence of about one affected individual per million live births (1), systematic data on MPS VI heart disease are hard to obtain and, because of the different diagnostic methods used, difficult to compare. In general, mucopolysaccharidoses affect mitral, aortic, tricuspid and pulmonary valves in decreasing order (5). In MPS VI, almost $100 \%$ of the patients exhibit mitral and/or aortic regurgitation by auscultation, heart catheterization or echocardiography $(5,6,28)$. MPS VI mice revealed histologic alteration and GAG storage in all heart valves investigated. By echocardiography, mitral thickening was detected in 4 of 10 MPS VI mice. Two of these mice showed mitral insufficiency and one mouse presented with aortic regurgitation. Physiologically, $15 \%$ of senescent mice older than one year develop aortic insufficiencies and mitral regurgitations are detected by echocardiography in $10 \%$ of aged mice (24). Thus, for MPS VI mice aortic insufficiency occurs at the frequency expected in wild-type mice, but mitral regurgitation in MPS VI mice seems to occur somewhat more frequently than expected in the wild type. In contrast to MPS VI patients $(1,29)$, calcification of heart valves was not observed in MPS VI mice. Thus it seems that valve insufficiency in the MPS VI mouse model is, despite the extensive GAG storage in heart valves, not as frequently observed as in MPS VI patients.

Some MPS VI patients develop a cardiomyopathy with cardiac enlargement (29). However, heart dimensions in MPS VI mice are not significantly altered up to an age of 12 mo, which represents about half the lifespan of a laboratory mouse. Reduced indices of myocardial performance, i.e. reduced shortening fraction, have been reported for 3 of 11 MPS VI patients investigated by cardiac catheterization or echocardiography $(5,28,29)$. In addition, case reports with clinical heart failure in MPS VI have been published (30, $31)$. In contrast to the relatively low frequency of impaired myocardial contraction in MPS VI patients, an important finding of the present study was the clear decrease of the shortening fraction in all MPS VI mice ranging from $17.3 \%$ to $30.5 \%$ compared with $34.5 \%-44.3 \%$ in wild-type controls. This reduced myocardial contraction of MPS VI mice is mainly due to an increased end-systolic left ventricular diameter. Consequently, diastolic suction function of the LV is also impaired in MPS VI mice as demonstrated by the reduced $V_{\max }$ of the mitral E-Wave. In contrast, contraction of the left atrium of MPS VI mice was not significantly impaired as indicated by comparable velocities of the mitral A-Wave in wild-type and MPS VI mice. There was no clear indication for LV-hypertrophy as a potential explanation of the LV-wall stiffening in MPS VI mice. Thus, interstitial accumulation of GAG storage material is likely to impair LV contraction by increasing the stiffness of the ventricle, which results in the markedly reduced cardiac output observed in the MPS VI mouse. In summary, the heart of MPS VI mice shows the typical valve histopathology as seen in MPS VI patients, but valve impairment occurs less fre- quently in MPS VI mice. In contrast, compromised myocardial function occurs consistently in MPS VI mice and, therefore, more frequently than in MPS VI patients. The latter finding may be due to a greater extent of interstitial GAG storage in MPS VI mice compared with patients, but quantitative data on GAG storage in human MPS VI myocardium are not available at present.

Atrophy and swelling of the optic nerve have been occasionally described in MPS VI patients $(4,32)$, yet no such alterations were found in MPS VI mice. However, the optic nerve involvement and spinal cord compression frequently occurring in MPS VI patients (33-36), can best be explained by GAG-storage in the fibroblasts of the dura mater. Although the spinal cord of MPS VI mice was not investigated in this study, histologic changes and GAG-storage in the dura mater around the optic nerve were detected in a single ASB-deficient mouse indicating that dura involvement is not a consistent feature of the present MPS VI mouse model.

Corneal opacities and corneal clouding are often observed in all forms of MPS VI $(1,3)$. Corneal transplantation for treatment of these symptoms has been performed in patients with only limited success $(37,38)$. Thus, the development of curative therapies should also aim for prevention or reversal of corneal symptoms. All MPS VI mice show marked alterations of keratocytes in the corneal epithelium and disarrangement of collagen fibrils and GAG storage in the stroma. Besides the MPS VI mice, the other animal models of MPS VI also show impairment of corneal epithelia and stroma $(10,39)$. However correction of lysosomal storage in keratocytes by enzyme replacement therapy in feline MPS VI proved to be unsuccessful for the correction of cartilagechondrocytes, even when the enzyme was administered in high doses starting at birth. Hence, analysis of the cornea should be considered a valuable parameter in therapy trials of the MPS VI mouse model.

\section{CONCLUSION}

In conclusion, ASB-deficient mice provide a model of MPS VI that is not only characterized by skeletal dysplasia but also by damage of the cornea and functional impairment of the heart. This will allow the assessment of the efficiency of enzyme replacement therapy as well as somatic gene therapy in this animal model with regard to the clinically relevant manifestations of this lysosomal storage disease.

Acknowledgment. The authors thank Ulrike Reif for excellent technical assistance and Marie Follo for her editorial assistance.

\section{REFERENCES}

1. Neufeld EF, Muenzer J 2001 The Mucopolysaccharidoses. In: Scriver CR, Beaudet AL, Sly WS, Valle D (eds) The Metabolic and Molecular Bases of Inherited Diseases. McGraw-Hill Inc., New York, pp 3422-3450

2. Litjens T, Hopwood JJ 2001 Mucopolysaccharidosis type VI Structural and clinical implications of mutations in N-acetylgalactosamine-4-sulfatase. Hum Mutat 18:282295

3. Laver NM, Friedlander MH, McLean IW 1998 Mild form of Maroteaux-Lamy syndrome: corneal histopathology and ultrastructure. Cornea 17:664-668

4. Collins ML, Traboulsi EI, Maumenee IH 1990 Optic nerve head swelling and optic atrophy in the systemic mucopolysaccharidoses. Ophthalmology 97:1445-1449 
5. Wippermann CF, Beck M, Schranz D, Huth R, Michel-Behnke I, Jüngst BK 1995 Cardiovascular changes in the mucopolysaccharidoses. In: Böhles H, Hofstetter R, Sewell AC (eds) Metabolic Cardiomyopathy. Wissenschaftliche Verlagsgesellschaft $\mathrm{mbH}$, Stuttgart

6. Wippermann CF, Beck M, Schranz D, Huth R, Michel-Behnke I, Jungst BK 1995 Mitral and aortic regurgitation in 84 patients with mucopolysaccharidoses. Eur J Pediatr 154:98-101

7. Herskhovitz E, Young E, Rainer J, Hall CM, Lidchi V, Chong K, Vellodi A 1999 Bone marrow transplantation for Maroteaux-Lamy syndrome (MPS VI): long- term follow-up. J Inherit Metab Dis 22:50-62

8. Vine DT, McGovern MM, Haskins ME, Desnick RJ 1981 Feline mucopolysaccharidosis VI: purification and characterization of the resident arylsulfatase B activity. Am J Hum Genet 33:916-927

9. Crawley AC, Yogalingam G, Muller VJ, Hopwood JJ 1998 Two mutations within a feline mucopolysaccharidosis type VI colony cause three different clinical phenotypes. J Clin Invest 101:109-119

10. Yoshida M, Ikadai H, Maekawa A, Takahashi M, Nagase S 1993 Pathological characteristics of mucopolysaccharidosis VI in the rat. J Comp Pathol 109:141-153

11. Yoshida M, Noguchi J, Ikadai H, Takahashi M, Nagase S 1993 Arylsulfatase B-deficient mucopolysaccharidosis in rats. J Clin Invest 91:1099-1104

12. Neer TM, Dial SM, Pechman R, Wang P, Oliver JL, Giger U 1995 Clinical vignette. Mucopolysaccharidosis VI in a miniature pinscher. J Vet Intern Med 9:429-433

13. Gasper PW, Thrall MA, Wenger DA, Macy DW, Ham L, Dornsife RE, McBiles K, Quackenbush SL, Kesel ML, Gillette EL, Hoover EA 1984 Correction of feline arylsulphatase B deficiency (mucopolysaccharidosis VI) by bone marrow transplantation. Nature 312:467-469

14. Crawley AC, Brooks DA, Muller VJ, Petersen BA, Isaac EL, Bielicki J, King BM, Boulter CD, Moore AJ, Fazzalari NL, Anson DS, Byers S, Hopwood JJ 1996 Enzyme replacement therapy in a feline model of Maroteaux-Lamy syndrome. J Clin Invest 97:1864-1873

15. Byers S, Crawley AC, Brumfield LK, Nuttall JD, Hopwood JJ 2000 Enzyme replacement therapy in a feline model of MPS VI: modification of enzyme structure and dose frequency. Pediatr Res 47:743-749

16. Simonaro CM, Haskins ME, Kunieda T, Evans SM, Visser JW, Schuchman EH 1997 Bone marrow transplantation in newborn rats with mucopolysaccharidosis type VI: biochemical, pathological, and clinical findings. Transplantation 63:1386-1393

17. Simonaro CM, Haskins ME, Abkowitz JL, Brooks DA, Hopwood JJ, Zhang J, Schuchman EH 1999 Autologous transplantation of retrovirally transduced bone marrow or neonatal blood cells into cats can lead to long-term engraftment in the absence of myeloablation. Gene Ther 6:107-113

18. Evers M, Saftig P, Schmidt P, Hafner A, McLoghlin DB, Schmahl W, Hess B, von Figura K, Peters C 1996 Targeted disruption of the arylsulfatase B gene results in mice resembling the phenotype of mucopolysaccharidosis VI. Proc Natl Acad Sci U S A 93:8214-8219

19. Romeis B 1989 Mikroskopische Technik. Urban und Schwarzenberg, Munich

20. Watson GL, Sayles JN, Chen C, Elliger SS, Elliger CA, Raju NR, Kurtzman GJ, Podsakoff GM 1998 Treatment of lysosomal storage disease in MPS VII mice using a recombinant adeno-associated virus. Gene Ther 5:1642-1649

21. Fentzke RC, Korcarz CE, Shroff SG, Lin H, Sandelski J, Leiden JM, Lang RM 1997 Evaluation of ventricular and arterial hemodynamics in anesthetized closed-chest mice. J Am Soc Echocardiogr 10:915-925
22. Patten RD, Aronovitz MJ, Deras-Mejia L, Pandian NG, Hanak GG, Smith JJ, Mendelsohn ME, Konstam MA 1998 Ventricular remodeling in a mouse model of myocardial infarction. Am J Physiol 274:H1812-1820

23. Collins KA, Korcarz CE, Shroff SG, Bednarz JE, Fentzke RC, Lin H, Leiden JM, Lang RM 2001 Accuracy of echocardiographic estimates of left ventricular mass in mice. Am J Physiol Heart Circ Physiol 280:H1954-1962

24. Patten RD, Aronovitz MJ, Bridgman P, Pandian NG 2002 Use of pulse wave and color flow Doppler echocardiography in mouse models of human disease. J Am Soc Echocardiogr 15:708-714

25. Schmidt AG, Gerst M, Zhai J, Carr AN, Pater L, Kranias EG, Hoit BD 2002 Evaluation of left ventricular diastolic function from spectral and color M-mode Doppler in genetically altered mice. J Am Soc Echocardiogr 15:1065-1073

26. Stypmann J, Glaser K, Roth W, Tobin DJ, Petermann I, Matthias R, Monnig G, Haverkamp W, Breithardt G, Schmahl W, Peters C, Reinheckel T 2002 Dilated cardiomyopathy in mice deficient for the lysosomal cysteine peptidase cathepsin L. Proc Natl Acad Sci U S A 99:6234-6239

27. Williams RV, Lorenz JN, Witt SA, Hellard DT, Khoury PR, Kimball TR 1998 End-systolic stress-velocity and pressure-dimension relationships by transthoracic echocardiography in mice. Am J Physiol 274:H1828-1835

28. Krovetz LJ, Schiebler GL 1972 Cardiovascular manifestations of the genetic mucopolysaccharidoses. Birth Defects 8:188-193

29. Schieken RM, Kerber RE, Ionasescu VV, Zellweger H 1975 Cardiac manifestations of the mucopolysaccharidoses. Circulation 52:700-705

30. Fong LV, Menahem S, Wraith JE, Chow CW 1987 Endocardial fibroelastosis in mucopolysaccharidosis type VI. Clin Cardiol 10:362-364

31. Hayflick S, Rowe S, Kavanaugh-McHugh A, Olson JL, Valle D 1992 Acute infantile cardiomyopathy as a presenting feature of mucopolysaccharidosis VI. J Pediat 120:269-272

32. Kenyon KR 1976 Ocular manifestations and pathology of systemic mucopolysaccharidoses. Birth Defects Orig Artic Ser 12:133-153

33. Wald SL, Schmidek HH 1984 Compressive myelopathy associated with type VI mucopolysaccharidosis (Maroteaux-Lamy syndrome). Neurosurgery 14:83-88

34. Young R, Kleinman G, Ojemann RG, Kolodny E, Davis K, Halperin J, Zalneraitis E, DeLong GR 1980 Compressive myelopathy in Maroteaux-Lamy syndrome: clinical and pathological findings. Ann Neurol 8:336-340

35. Seto T, Kono K, Morimoto K, Inoue Y, Shintaku H, Hattori H, Matsuoka O, Yamano T, Tanaka A 2001 Brain magnetic resonance imaging in 23 patients with mucopolysaccharidoses and the effect of bone marrow transplantation. Ann Neurol 50:79-92

36. Boor R, Miebach E, Bruhl K, Beck M 2000 Abnormal somatosensory evoked potentials indicate compressive cervical myelopathy in mucopolysaccharidoses. Neuropediatrics 31:122-127

37. Aguirre G, Raber I, Yanoff M, Haskins M 1992 Reciprocal corneal transplantation fails to correct mucopolysaccharidosis VI corneal storage. Invest Ophthalmol Vis Sci $33 \cdot 2702-2713$

38. Schwartz MF, Werblin TP, Green WR 1985 Occurrence of mucopolysaccharide in corneal grafts in the Maroteaux- Lamy syndrome. Cornea 4:58-66

39. Alroy J, Haskins M, Birk DE 1999 Altered corneal stromal matrix organization is associated with mucopolysaccharidosis I, III and VI. Exp Eye Res 68:523-530 